\title{
The Construction of Empirical Research Model on New Generation of Migrant Worker's Urban Inclusion: from a Perspective of Psychological, Social and Human Capitals
}

\author{
Cao Yanling \\ Yatai School of Business Administration, Jilin University of Finance and Economics, Changchun, China \\ 328465451@qq.com
}

Keywords: new generation of migrant worker; psychological capital; social capital; human capital

\begin{abstract}
Based on the central role of human in the process of Chinese New Urbanization, considering their uniqueness and semi-citizenry, this paper did some researches on how to resolve the problem of the new generation of migrant worker's urban inclusion in the context of gradually liberating the household registration system in the process of New Urbanization through constructing the empirical research model on new generation of migrant worker from a perspective of psychological, social and human capitals.
\end{abstract}

\section{Introduction}

There's a phenomenon that the new generation of migrant worker integrates city deeply in economic aspect but not in social and psychological parts in the process of their urban inclusion. Traditional binary structure resulting from household system is evolving into a new one that new generation of migrant worker is in the status of semi-citizenry, which made their dreams of becoming true citizen and integrate into city encounter lots of embarrasses and resignations.

With the continuous advance of New Urbanization, replacing the physical urbanization, human has become the core of New Urbanization strategy, therefore humanistic care and concept should be injected in the course of urbanization, which would bring humanistic glory to every corner of new-type city. Although a new household registration policy of comprehensively liberalizing the household registration limit in designated town and small city and opening up the limit in middle-size city in order so as to let migrants enjoy residential treatment increasingly. However, even if the new generation of migrant workers can leap over household registration obstacles caused by urban-rural dual system, they still should live a urban lifestyle, form a urban value, possess psychological capital needed by integration into city, obtain social capital in order to get affectional acceptance by native citizens, and own human capital so that to live and work in urban area in peace and contentment.

Based on the central role of human in the process of Chinese New Urbanization, considering their uniqueness and semi-citizenry, this paper did some researches on how to resolve the problem of the new generation of migrant worker's urban inclusion in the context of gradually liberating the household registration system in the process of New Urbanization through constructing the empirical research model on new generation of migrant worker from a perspective of psychological, social and human capitals.

\section{Influencing Factors on the New Generation of Migrant Worker's Urban Inclusion}

In summary, there are several factors influencing the new generation of migrant worker's urban inclusion:

\subsection{Institutional Factors}

The household registration system, farmland system, urban employment system with household registration system as its core, urban housing offering system, social security system, education 
system impedes people's rural-urban migration (Lu Xianghu, 2005). But in recent years, institutional constraints have been weakened in new generation of migrant worker's cognition. At national level, peasants' land rights have been strengthened in the aspects of policies and laws continuously, thus improving the migrant freedom of migrant workers. City identification and attitude towards land have strongly relevant to the migrant workers' tendency to remain in the city (Zeng Xuhui, Qin Wei, 2003).

\subsection{Economic Factors}

From the perspective of cost-return, after weighting the income, living cost, family's income, the place of the future development trend of migrant workers' moving into and moving out, the migrant workers decide where to settle down. Zheng Zhang (2006) found that annual income, anticipated working years and housing costs are several main factors influencing migrant workers' settling in city. Some skilled workers have better economic condition due to their longer expected working life. The rural-urban income gap affects the migrant workers' perpetual migration mainly (Ma Jiujie, Meng Fanyou, 2003). The lower the economic development degree in the region of moving out, the more the migrant workers tend to settle down in city (Lie Luo,2010). The more developed the cities they working at, the higher the consuming level and living cost, the weaker the migrant workers' tendency to resident in city (Ye Pengfei, 2011).

\subsection{Human Capital Factors}

The final results of migrant workers' inflowing are affected by their individual human conditions to a great extent. Migrant workers' human capital can be divided to several indicators, such as education level, skill training degree, migrant years, working experience (Zhao Yandong, , Wang Fenyu, 2002). The higher the degree of human capital, the higher possible the migrant workers find the developing opportunities, the easier they are adapted to and identify with the city working and living conditions (Cai He, Wang Jin,2007). In general, the migrant workers with high education level tend to resident in the city they working at and are more apt to integrate in the city (Li Qiang, 2003; Li Zhenzhen, Chen Lin,2010; Ren Yuan, Qiao Nan, 2010; Fan,2011; Luo Chi, 2012). But at peasant, in generally, the literacy level of migrant worker is relatively low, therefore, enhancing their employability seems more important. Continuously improving their survival ability by skill training is crucial to migrant workers’ perpetual residency in city.

\subsection{Social Network and Social Psychology Facts}

The affective feature relation and tool feature relation at the two ends of social network continuum dramatically affect the migrant workers' will to remain city (Wang Yijie, 2005). Cai Jin, Wang Jin (2007) found the higher identity about urban life style the migrant workers have, the stronger will they migrate to city. Guo Xinghua (2005) found that the cultural and interpersonal distance between the new generation of migrant workers and urban citizens are increasingly broadening, therefore they are lack of mutual social identification. More and more peasants choose to associate with other peasants of their inner circle, then, the closed intercourse space result in single cultural communication featured with voluntary isolation. Accordingly, the living area appears a feature of isolated island. On the other hand, strong local favors, familiar lifestyle would generate a kind of powerfully affective pull. Migrant workers continuously create psychological anxiety due to this sort of push-and-pull game between urban and rural areas. What confuse them is whether positively integrate or flee urban areas, which lead to create identification involution, marginalization, and isolated fusion (Wang Chunguang, 2006, 2011; Li Qiang, 2011).

Many Chinese scholar also found that some factors such as gender, age, marital status will influence the choice of migrant workers' future settlements. 


\section{Empirical Research Hypothesis on New Generation of Migrant Worker's Urban Inclusion: from a Perspective of Psychological, Social and Human Capitals}

\subsection{Human Capital Factors}

Human capital affects migrant workers' urban inclusion through an intermediate variable of capability. First of all, some factors such as education level, age are developing human capitals that the migrant workers have developed before they move to city to work, which decide their capability of finding jobs. Secondly, some factors, such as whether received training, professional skill level, qualifications are developing capital that has been formed after migrant workers moved into urban areas. These factors will determine the income of the migrant workers, consequently influence their urban inclusion ability.

It is easy to infer that human capital will affect the migrant workers' urban inclusion ability, including abilities of economic inclusion, social inclusion and psychologic inclusion. Consequently, we can make the following hypothesis:

H1a: Human capital influences the new generation of migrant workers' social inclusion positively;

H1b: Human capital influences the new generation of migrant workers' psychological inclusion positively;

H2: Human capital influences the new generation of migrant workers' economic inclusion positively.

\subsection{Social Capital Factors}

One's social network is composed of family members, friends and some acquaintances providing social supports emotionally and materially. Ye Jingyi, Tong Xuemin thought that original social capital didn't influence migrant workers' income significantly, while new-type social capital would affect dramatically. Original social capital hindered the migrant workers' identification and affiliation, however the new-type social capital belonging to idiosyncratic capital can improve the migrant workers' urban inclusion. Wang Chunchao considered that integrated social network was a kind of closed network capital, formed by methods of geographical and family relationships; nevertheless, bridging social capital is a sort of social capital created by crossing and joining among different flowing groups. Integrated and bridging social relationship affect the migrant workers' income positively. Therefore, these two kinds of social capitals have supplementary effects on the improvement of the migrant workers' economic status.

So, the factor of social capital will affect the migrant workers' urban inclusion ability, including abilities of economic inclusion, social inclusion and psychologic inclusion. Consequently, we can make the following hypothesis:

H3a: Social capital influences the new generation of migrant workers' social inclusion positively;

H3b: Social capital influences the new generation of migrant workers' psychological inclusion positively;

H4: Social capital influences the new generation of migrant workers' economic inclusion positively.

\subsection{Psychological Capital Factors}

As a core psychological element, psychological capital transcends human capital and social capital. Goldsmith considers that psychological capital includes how a person think oneself, the attitude towards work, ethical orientation and the general view of life. The effects of psychological capital on migrant workers' ability of urban inclusion are represented as their influences to migrant workers' employability, the confidences when they face difficulties. For example, if a new generation of migrant worker owning higher self-efficacy believes he have better skills and capabilities, he will work better in the future and have more confidence to find a better job. These faiths will turn into a high level of employability and become an impetus to hunt a job. Then there's 
a research conclusion that the new generation of migrant workers' psychological capital affects their urban inclusion ability.

H5a: Psychological capital influences the new generation of migrant workers' social inclusion positively;

H5b: Psychological capital influences the new generation of migrant workers' psychological inclusion positively;

H6: Psychological capital influences the new generation of migrant workers' economic inclusion positively.

\subsection{Economic Inclusion, Social Inclusion and Psychological Inclusion}

Kai Tian thinks that these three levels have a relationship of one gradually promoting the other two levels. At first, one should obtain some supports come from economic level, which is the basis of adapting to urban life; beyond the economic level, migrant worker must integrate urban area in aspects of social intercourse and living, which is a further requirement to fit urban area; cultural and psychological fit is the highest level, which reflects migrant worker's psychological requirement. He makes a conclusion that the process which the migrant workers adapt city is a socialization one through a three-level analysis.

Therefore, the economic inclusion of new generation of migrant workers directly determine whether they can survive in city. Comparatively, it is easier to be realized for the economic inclusion. With the realization of economic inclusion, the new generation of migrant workers will integrate socially and psychologically. Economic inclusion plays an intermediating role between the three kinds of capital and social inclusion, psychological inclusion, so the three kinds of capital influence new generation of migrant workers' social and psychological inclusion.

H7a: Economic inclusion influences the new generation of migrant workers' social inclusion positively;

H7b: Economic inclusion influences the new generation of migrant workers' psychological inclusion positively;

H8aa: Economic inclusion plays an intermediating role between human capital and social capital;

H8ab: Economic inclusion plays an intermediating role between human capital and psychological capital;

H8ba: Economic inclusion plays an intermediating role between social capital and psychological capital;

H8bb: Economic inclusion plays an intermediating role between social capital and psychological inclusion;

H8ca: Economic inclusion plays an intermediating role between psychological capital and social inclusion;

H8ca: Economic inclusion plays an intermediating role between psychological capital and the psychological inclusion.

\section{The Construction of Empirical Research Model on New Generation of Migrant Workers' Urban Inclusion: from a Perspective of Psychological, Social and Human Capitals}

The empirical research model can be made according to the above hypotheses, as shown in Figure 1. New generation of migrant worker's human capital, social capital and psychological capital influence his economic inclusion, social inclusion and psychological inclusion; new generation of migrant worker's human capital, social capital and psychological capital affect social inclusion and psychological inclusion through economic inclusion. The economic inclusion plays an intermediating role. 
$\mathrm{H} 1 \mathrm{~b}$

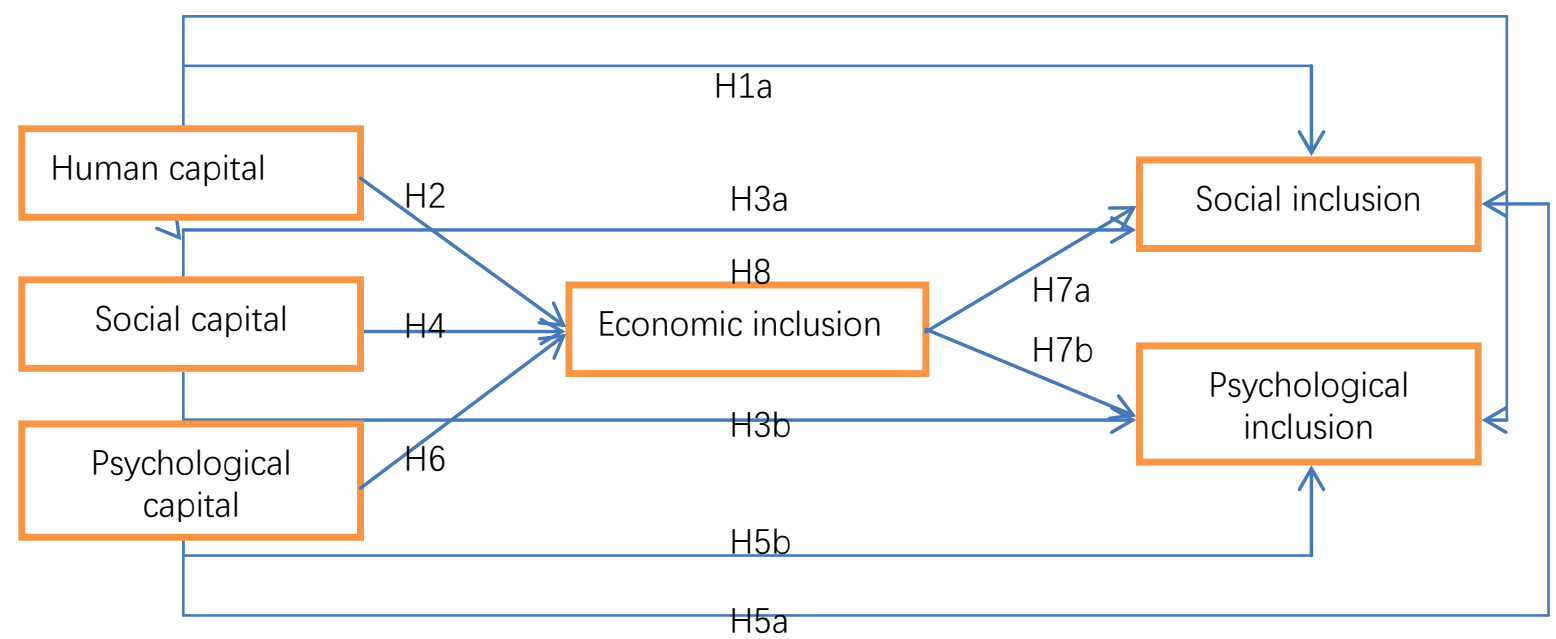

Figure 1 Empirical research model on new generation of migrant worker's urban inclusion: from a perspective of psychological, social and human capitals.

\section{References}

[1] Wang Chunguang. (2010) An Awareness on the New Generation of Migrant Worker's Urban Integration. Population Research. 3, 31-33.

[2] Wang Dianli, Liu Baojun, Lou Suping. (2011) The New Generation of Migrant Worker's Urban Integration: Construction of Analysis Framework and Research Analysis. Chinese Public Administration. 2, 111-115.

[3] Su Tong. (2015) Institutional Factors Analysis on New Generation of Migrant Worker's Citizenization, Economic Research Guide. 14, 15-17.

[4] Baron R A G. (2000) Beyond Social Capital: How Social Skills and Enhance Entrepreneurs' Success. Academy of Management Executive. 14,15.

[5] Kumar C S. (2006) Human Capital and Growth Empirics. The Journal of Developing Areas. 40, 5 .

\section{Appendix}

This paper is a periodic achievement of a Scientific Research Project of Jilin University of Finance and Economics (No. 2017B29) and 13th Five-Year Plan Scientific Research Project of Education Department of Jilin Province (No. JJKH20180487SK). 